\title{
O movimento dos sentidos de escravidão em artigos jornalísticos do Jornal Folha da Manhã do início do século XX
}

\author{
The movement of meanings of slavery in newspaper articles from the journal \\ Folha da Manhã in the beginning of the $20^{\text {th }}$ century
}

Carolina de Paula Machado ${ }^{1}$

Universidade Federal de São Carlos

\begin{abstract}
- RESUMO: Buscamos compreender, neste artigo, o que designa a palavra escravidão em artigos do jornal "Folha da Manhã", publicados entre os anos 20 e 30 do século XX. Essa pesquisa, que envolve também o jornal "Folha da Noite", faz parte de uma pesquisa maior intitulada "Argumentação, textualidade, e designação na semântica do Acontecimento: os sentidos nos diferentes modos de escravidão", que conta com o apoio da FAPESP, e é coordenada pela Profa. Soeli M. Schreiber da Silva e na qual sou pesquisadora associada. Realizada na perspectiva teórica da Semântica do Acontecimento, com esta pesquisa queremos observar que sentidos de escravidão estão presentes no funcionamento enunciativo de jornais de grande circulação no início do século XX, depois que a escravidão foi abolida, já era independente de Portugal há mais ou menos um século e vigorava o regime republicano. Nos recortes, analisamos a cena enunciativa e os domínios semânticos de determinação e, com isso, observamos uma rememoração de sentidos da época em que a escravidão vigorava no Brasil, como a antonímia com liberdade, mas ressignificada, no acontecimento enunciativo, como estado de escravidão, como feudalismo escravocrata, como tutela e autocracia quando o locutor-jornalista critica a República.
\end{abstract}

- PALAVRAS-CHAVE: Escravidão. Designação. Semântica. Enunciação. Liberdade.

- ABSTRACT: Through this article, we intend to understand what designates the word slavery in articles of the newspaper "Folha da Manhã" published in between the 1920s and 1930s of the 20th century. The research, to which this article is based on, is part of larger project entitle "Argumentation, textuality and designation in the Semantics of Happening: the meanings in the different ways of slavery" sponsored by FAPESP and it is coordinated by the Professor Soeli M. Schreiber da Silva and to It I am an associated researcher. Analyzed through the theoretical perspective of the Semantics of the Happening, to with this research we intend to observe which are the meanings of slavery presented in the enunciatively process of the well distributed journals from the beginning of the 20th century, after the Slavery Abolition, and trough the fact that Brazil had been independent from Portugal for almost a century and the Republican Regime was in mode. By the cutouts of the corpus we analyzed the enunciatively scene and de semantic domain of determination to which we observed the remembrance of the meanings from the times that the Slavery was in vogue place in Brazil with the antonyms as freedom, however, re-significated in the enunciatively event, as state of slavery, as slavery feudalism, as guardianship and autocracy when the speaker-journalist critics the Republic.

- KEYWORDS: Slavery. Designation. Semantics. Enunciation. Freedom.

Neste artigo $^{2}$, procuramos especificamente descrever o que significa a palavra escravidão no Jornal Folha da Manhã, em exemplares publicados em meados

\footnotetext{
${ }^{1}$ Doutora em Linguística pela UNICAMP. É professora do Departamento de Letras da Universidade Federal de São Carlos. É membro da Unidade de pesquisa em estudos históricos, políticos e sociais da linguagem (UEHPOSOL). carolinapmac@gmail.com
} 
da década de 30 do século $\mathrm{XX}^{3}$. Nosso objetivo geral da pesquisa é o de compreender quais sentidos da palavra escravidão circulam no funcionamento enunciativo durante a $1^{\text {a }}$ República brasileira, em um corpus constituído de artigos de jornais da Folha da Noite $^{4}$ e Folha da Manhã.

Nas análises que realizamos, observamos o movimento de sentidos da palavra escravidão, isto é, sentidos que rememoram um passado de enunciados sobre a escravidão dos negros e que são atualizados nos acontecimentos enunciativos dos jornais no início do século XX. Os sentidos da palavra escravidão estão relacionados, como veremos nos textos aqui analisados, dentre outras situações, a uma forma política nova para o Brasil, o regime Republicano, ou como chamam os historiadores, a " 1 a República". Trata-se de uma nova "qualidade de tempo", tal como afirmam Zancarini e Fournel (2008), que demanda uma "língua política" já que é preciso significar uma conjuntura em que havia muitas críticas ao regime republicano recém-constituído.

A palavra escravidão revelou-se uma palavra que simboliza algo dessas relações políticas nesse período. Do ponto de vista semântico, tem havido um movimento de sentidos da escravidão na medida em que os locutores-jornalistas reinscrevem essa palavra na nova conjuntura político-econômica e, com isso, os sentidos atribuídos à escravidão dos negros deslizam para significar o regime republicano na sociedade brasileira, revelando os conflitos políticos daquele momento, através da crítica ao governo republicano com a defesa do voto secreto.

\section{Designação, Cena Enunciativa e o Político}

Para descrevermos o movimento dos sentidos da palavra escravidão, o conceito de designação, definido do ponto de vista semântico-enunciativo, é central neste trabalho. Trata-se da "significação enquanto algo próprio das relações de linguagem, mas enquanto uma relação linguística (simbólica) remetida ao real, exposta ao real, ou seja, enquanto uma relação tomada na história" (Guimarães, 2002, p. 09).

A designação é uma forma de tratar do sentido no funcionamento enunciativo dos textos, do dizer em geral, que se constituem pelas relações entre as palavras, realizadas a partir das reescrituras e articulações e dependem do agenciamento enunciativo dos sujeitos divididos na enunciação e da relação com o já dito.

Pelo modo como o dizer é distribuído aos falantes, essa constituição dos sentidos é política, entendendo a política tal como define Guimarães:

(...) pela contradição de uma normatividade que estabelece (desigualmente) uma divisão do real e a afirmação de pertencimento dos que não estão incluídos. Deste modo o político é um conflito entre uma divisão normativa e desigual do real e uma redivisão pela qual os desiguais afirmam o seu pertencimento. Mais importante ainda para mim é que deste ponto de vista o político é incontornável porque o homem fala. O homem está sempre a assumir a palavra, por mais que esta lhe seja negada. (Guimarães, 2002, p. 16)

\footnotetext{
${ }^{2}$ Versão do texto originalmente apresentado no III ENSAD- Encontro Nacional em Semântica e Análise do Discurso: Marcha, Identidade e Fronteira e V Encontro em Análise do Discurso: Estudos Orlandianos em Foco, realizado na Universidade Estadual do Mato Grosso do Sul (UEMS), no período de 07 a 09 de Junho de 2017.

3 Nossa pesquisa, iniciada em 2016, faz parte de um projeto regular Fapesp maior (2015/16397-2) intitulado "Argumentação, textualidade, e designação na semântica do Acontecimento: os sentidos nos diferentes modos de escravidão", com o apoio da FAPESP, coordenado pela Profa. Soeli M. Schreiber da Silva e do qual sou pesquisadora associada.

${ }^{4}$ Uma primeira versão das análises do jornal "Folha da noite" foi apresentada em um artigo intitulado "Semântica e enunciação: a designação da palavra escravidão em artigos do jornal "Folha da Noite" do início do século XX". O artigo foi publicado na revista Entrepalavras da Universidade federal do Ceará.
} 
Assim, o Locutor, ao falar na cena enunciativa, pela relação com a temporalidade do acontecimento enunciativo, produz certos sentidos na enunciação, revelando o lugar social do qual fala. Porém, ele mostra-se como desconhecendo de que fala de um lugar social, enunciando apenas como um lugar de dizer como veremos adiante.

Como nos explica Elias de Oliveira (2014), a política ou o político, nessa perspectiva enunciativa, "diz respeito às divisões enunciativas na configuração do dizer, isto é, àquelas concernentes às representações dos sujeitos e aos gestos de afirmação de pertencimento desses sujeitos em relação a um objeto de dizer" (p. 41-42).

Para realizar nossa análise, observamos a cena enunciativa, isto é, onde ocorre a "assunção da palavra". Trata-se de observar os "modos específicos de acesso à palavra dadas as relações entre as figuras da enunciação e as formas linguísticas" (Guimarães, 2002 , p. 23). O Locutor, que se representa na enunciação como a fonte do dizer, enuncia sempre predicado pelo lugar social que o autoriza a falar (locutor-x ou 1-x). Mas, ao enunciar, o Locutor fala como se estivesse fora da história, desconhecendo que fala de um lugar social. Ele se representa como um lugar de dizer, isto é, como enunciador, que pode ser: individual, que retira o dizer das circunstâncias em que foi dito, atribuindo a si uma responsabilidade sobre o que diz; genérico, dizendo algo como um dizer genérico, que todos dizem como se fosse individual, como no caso dos ditos populares; universal, como se fosse uma verdade universal; e coletiva, representando uma coletividade.

Além dessa representação do sujeito na enunciação, utilizamos também a noção de posição-sujeito ${ }^{5}$ da Análise de Discurso, por possibilitar compreendermos que a produção de certos sentidos revela uma posição ideológica quando o regime republicano é criticado, o que nos permite compreender o direcionamento do dizer, o que estava em jogo no movimento dos sentidos de escravidão. Desse modo, nos baseamos na articulação do conceito de político da semântica enunciativa com o conceito de político da Análise de Discurso feita por Elias de Oliveira (2014) ${ }^{6}$.

Assim, mobilizamos o conceito de posição-sujeito por considerarmos, assim como a autora, ser produtivo aliar este conceito à análise da cena enunciativa. Ressaltamos importante parceria entre a Semântica do Acontecimento e a Análise de discurso, que trouxe contribuições inestimáveis para os estudos semânticos, principalmente pelo desenvolvimento da Análise de Discurso no Brasil pela profa. Eni Orlandi.

O movimento dos sentidos da palavra escravidão não é um movimento que acontece por causa de uma mudança semântica atribuída à língua em si mesma, como algo que acontece com o passar do tempo. Trata-se de um movimento que ocorre devido ao conflito dos sentidos, já que estes são divididos, e têm uma direção, pois os sujeitos enunciam de lugares sociais diferentes, de posições-sujeito diferentes. Esse movimento semântico revela uma disputa pelos sentidos que significam "algo do real". E isso se sustenta na história de enunciações, quando são rememoradas enunciações da época da escravidão dos negros no Brasil, ressignifcadas no presente do acontecimento enunciativo dos textos jornalísticos analisados, em que os locutores-jornalistas, no caso em que analisamos, criticam inúmeras situações como o fascismo na Itália, ou noticiam

\footnotetext{
${ }^{5}$ Segundo Guimarães (2002, p. 30) comentando Orlandi (1999) "falar e fazer-se sujeito é estar numa região do interdiscurso, de uma memória de sentidos".

${ }^{6}$ Ver Elias de Oliveira, "Sobre o funcionamento do político na linguagem" (2014). Neste artigo, a autora articula os dois conceitos de político, relação esta produtiva para a análise que realiza. Assim traz o conceito de Orlandi que define o político como "o fato de que o sentido é sempre dividido, tendo uma direção que se especifica na história, pelo mecanismo ideológico de sua constituição. Aí estão ligadas 3 noções - o político, o histórico e o ideológico(...)" (ORLANDI, 1996, pp. 21 e 22.)
} 
uma cerimônia espiritualista, ou, como temos visto se repetir nos artigos jornalísticos, na crítica ao sistema Republicano.

Como metodologia de análise, descrevemos e analisamos o processo de reescrituração ${ }^{7}$, em que a palavra é dita e redita e, nessa medida, os sentidos se constituem, e, também, a articulação nos enunciados, isto é, a relação de determinação de sentidos entre palavras/expressões que não se reescrevem.

A partir da análise desses procedimentos de textualidade, chegamos ao Domínio Semântico de Determinação (DSD), que representa aquilo que uma palavra designa no texto. Em nosso caso, partimos das ocorrências da palavra escravidão nos textos jornalísticos e estabelecemos recortes desses textos para compor o nosso corpus.

Passemos então às análises:

Análises

Recorte $1^{8}$

Folha da Manhã - 03/01/1926

"Os espiritualistas celebram a festa da fraternidade" - Como decorreu a cerimonia- palavras do sr. Henrique de Macedo.

“ (...) Se por espiritualismo quizer-se entender, não a ascese dos êxtases místicos ou o cego proselitismo dos sectários, mas o trabalho indefesso do homem a bem da liberdade humana, o labor justo e nobre em prol do ressurgimento moral de uma época, o intercambio das almas baseado na tolerância e no respeito mutuo e o intercambio de produtos sob o justo valor que o egoísmo não macule ou a ganancia não adultere, o direito da mulher respeitado na equivalência exata do direito do homem, a criança, órfã ou não, velada pelo estado, erguendo-se na vida sob a luz duma educação que lhe forme o caráter sem lhe escravizar a consciência em nenhum aspecto da escravidão, o criminoso, por um sistema penitenciário liberal e carinhoso, reivindicando-se, sob a égide de um trabalho de moral e de officina, sem imposição de um credo que lhe seja hostil à evolução, para as dignidades da vida no futuro, então muito, quiça, ter-se-á que fazer sobre a terra ainda pesada e dura. (...)

Este recorte é um trecho de um discurso proferido pelo senhor Henrique de Macedo, pessoa que presidiu a cerimônia da "festa da fraternidade" ocorrida em janeiro de 1926, evento este dos chamados "espiritualistas" que está sendo noticiado. O discurso é reproduzido pelo locutor-jornalista, na forma de discurso direto, transferindo o seu espaço autorizado de fala para outro locutor, no caso, um "espirituralista".

No recorte em questão, temos o enunciado em que o locutor-espiritualista explica, no modo de dizer coletivo, em nome dos que seguem os dogmas do espiritualismo, o que se deve entender como sendo o espiritualismo com relação à educação das crianças:

(...)a criança, órfã ou não, velada pelo estado, erguendo-se na vida sob a luz duma educação que lhe forme o caráter sem lhe escravizar a consciência em nenhum aspecto da escravidão, (...)

\footnotetext{
${ }^{7}$ O procedimento de reescrituração, segundo Guimarães (2007) pode se dar de diversas formas: por repetição, por substituição, por elipse, por expansão, por condensação, por definição. Os diversos modos de redizer o dito podem produzir relações de sentido como sinonímia, antonímia, especificação, generalização, desenvolvimento, totalização, enumeração, hiperonímia, hiponímia.

${ }^{8}$ Procuramos manter a ortografia original dos textos.
} 
Temos a ocorrência do substantivo escravidão, assim como a do verbo escravizar, sem ocorrências de reescriturações por repetição dessas palavras.

O verbo escravizar está articulado à consciência, determinando-a, formando então o sintagma "escravizar a consciência" que nos revela que a escravidão não é voltada para o trabalho braçal do indivíduo, como era na escravidão dos negros, mas apenas da consciência, no sentido de escravizar a consciência pela religião.

Assim temos nesse recorte uma articulação entre o verbo escravizar e seu complemento que nos mostra um movimento da ação de escravizar o corpo (do negro), para a ação de 'escravizar a consciência' por meio de uma doutrina religiosa.

Podemos observar que o locutor-espiritualista enuncia inscrito em posiçãosujeito religiosa, embora refute a "cegueira" doutrinária. Como não temos reescriturações da palavra escravidão, apenas a relação de sentido com o sintagma "escravizar a consciência", não faremos o esquema do DSD.

Passemos ao próximo recorte:

\section{Folha da Manhã - 04/01/1926}

\section{Temos uma lei... - Autor: Bertho Conde}

"(...) Felizmente ninguém melhor que a colônia italiana conhece o tal "fascismo" e conhece a razão que milita a favor dos antifascistas. $\mathrm{O}$ proletário italiano aqui residente sabe que todas as liberdades de que ainda goza as deve exclusivamente à nossa organização política, sabe que os seus irmãos de infortúnio, residentes na pátria, regressaram ao estado de escravidão em que viviam na idade média, sabem que a transplantação desse partido para a nossa terra é uma ameaça á sua vida e ás suas aspirações individuais e coletivas, razão pela qual nenhum membro da colônia se deixou enganar pela insidiosa intriga."(...)

O locutor-jornalista trata da situação dos italianos na Itália e no Brasil, como que reproduzindo uma opinião negativa sobre o fascismo como enunciador genérico. Temos o sintagma estado de escravidão ao invés de escravidão simplesmente. No sintagma nominal "estado de escravidão", a escravidão não é algo permanente, nem natural, mas um estado, uma condição, vinculada ao sistema político fascista que vigorava na Itália, sendo que os Italianos, no Brasil, eram "livres". Observando o texto transversalmente, podemos perceber que estado de escravidão está no domínio de antonímia de liberdade gozada pelos italianos que migraram para o Brasil.

Podemos representar então esta relação de sentidos pelo seguinte Domínio Semântico de Determinação 9 :

\section{Liberdade}

\section{Estado de Escravidão}

Rememora-se neste acontecimento enunciativo a antonímia entre liberdade e escravidão, que é mobilizada na cena enunciativa para determinar o sentido de estado

\footnotetext{
${ }^{9}$ Conforme Guimarães (2007), o domínio semântico de determinação é composto pelo sinal "f” entre duas palavras que significa que o sentido de uma palavra "determina" o sentido de outra, em qualquer direção que estiver. O traço maior, " ", que divide o DSD significa a antonímia e o traço menor "-" entre duas palavras significa a relação semântica de sinonímia. É importante destacar que essas relações semânticas são constituídas enunciativamente, ou seja, não são pré-estabelecidas, diferindo-se, assim, de uma posição referencialista.
} 
de escravidão, embora estado de escravidão e escravidão já constituam um deslizamento de sentido, pois o estado não é algo permanente, nem inato, se considerarmos uma discursividade escravocrata, mas resultado de uma política de governo.

Vejamos agora o terceiro recorte. Nele, não é dito o nome do jornalista, é feita uma introdução à notícia, e em seguida abrem-se aspas e o autor é a pessoa entrevistada, o "sr. João Freire de Oliveira, ex-candidato a vereador pela 'Colligação Operária".

Folha da Manhã - 06/01/1926 - "Operariado" - sem autor

"Santos de hoje não é mais Santos de 1880, época do feudalismo escravocrata que negava a todos os direitos aos produtores, inclusive o de se instruírem, como na idade-média, Santos encerra em suas páginas históricas os episódios mais legítimos e grandiosos de libertação. Quer falemos da abolição da escravatura, por ocasião da fuga em massa dos escravos das fazendas, onde nas quebradas do Jabaquara os fugitivos encontravam o devido abrigo, cujo fato teve enorme repercussão e que se avolumou de tal forma, que de toda a parte começaram a surgir protestos uníssonos contra a escravidão; quer falemos da propaganda republicana, ou remontemos às páginas mais antigas das descobertas científicas ou da literatura, encontramos sempre como vanguardeiro de todos esses emprehendimentos. Se meditarmos então sobre a questão social no Brasil, verificamos a publicação do primeiro jornal socialista em 1896, nesta cidade, intitulado "A Questão Social", como consequência dos pruridos da organização sindical daquela época.

É pois por muitíssimas razões explicáveis que de Santos tenha partido, pela primeira vez no Brasil, a iniciativa de arregimentação eleitoral da classe operária com um programa e orientação própria.

Não fomos, é certo, compreendidos, isso, porque a mentalidade do operariado eleitor no Brasil é ainda a do antigo escravo da fazenda, obediente e servil ao senhor doutor. Acreditam mais nas charlatanices dum bacharel que nas verdades dum companheiro de classe. Pessimistas, acomodatícias e muito interesseiros. (...)

O locutor-jornalista dá voz ao locutor-entrevistado na cena enunciativa, que enuncia como enunciador coletivo, representado pelo pronome "nós", colocando as impressões dessa coletividade sobre o que acontecia no passado na cidade de Santos. Ele retoma o passado da cidade, a qual viveu um feudalismo escravocrata e "episódios grandiosos de libertação", e, pelo memorável ${ }^{10}$, entendemos que abolição da escravatura reescreve por substituição os "episódios grandiosos de libertação".

O locutor destaca o passado da cidade de Santos quando aconteceram episódios de libertação dos negros, de organização sindical, de defesa do social, de organização eleitoral dos operários.

O sintagma nominal feudalismo escravocrata é reescrito por substituição por condensação pela palavra escravidão. O sintagma feudalismo escravocrata traz um sentido específico à escravidão por remeter, pelo passado de enunciações que recorta, a um sistema econômico, político e social que vigorou durante a Idade Média, em que o

\footnotetext{
${ }^{10}$ Guimarães (2002) define a enunciação como "acontecimento de linguagem" caracterizado como "diferença na sua própria ordem" (p. 11) pois o acontecimento define a sua temporalidade, isto é, o presente do acontecimento possibilita a projeção da interpretação que seria a futuridade. Nesse caso, é o passado que faz com que o presente signifique e há o futuro de interpretação, sendo o passado o que o autor chama de "memorável", caraterizado como "rememoração de enunciações" recortada pelo presente da enunciação.
} 
trabalhador (vassalo) trabalha, numa relação de submissão, na terra de propriedade do senhor feudal (suserano) ${ }^{11}$.

Esse locutor entrevistado fala do lugar social de operário, embora se distancie do "operariado eleitor" e enuncia de uma posição-sujeito que se opõe à classe dos "senhores doutores" e do "operariado eleitor". O passado feudal e escravocrata parece estar sendo rememorado para criticar o eleitor operariado que, segundo o locutor, ainda tem uma mentalidade "servil" e "obediente" acreditando no "senhor doutor" e não nos companheiros de classe.

A escravidão configura-se também como antônima de episódios grandiosos de libertação e abolição da escravatura. Vejamos o DSD:

\section{Feudalismo escravocrata $\dashv$ Escravidão}

Abolição da escravatura F episódios grandiosos de libertação

Temos então novamente, como vemos no DSD, a antonímia com liberdade. Também, é realizada uma articulação entre os sintagmas Feudalismo e escravocrata, o que traz uma relação semântica que aproxima o trabalho escravo ao trabalho feudal, sendo este costumeiramente uma forma de trabalho depreciada por se entender que o vassalo era explorado pelo senhor feudal, numa relação de submissão. Essa aproximação ente trabalho escravo e trabalho no sistema feudal, formas de trabalho rememoradas do passado, parece sustentar, depois, a crítica que é feita ao operariado eleitor no presente do acontecimento do texto. Revela-se, pela relação de sentido de escravidão com o feudalismo, o conflito, na cena enunciativa, no interior da classe operária.

Passemos ao último recorte a ser analisado:

\section{Jornal Folha da Manhã- 16/02/1926}

\section{“Psycologia da política brasileira" - Autor: Mario Pinto Serva.}

Em todos os países civilizados, os políticos, estadistas e governantes, para serem eleitos e reeleitos, em quaisquer funções públicas, procuram bem servir o público, satisfazendo-lhe aspirações e desejos, pois que este nas eleições tem a liberdade ampla de escolher quem bem quiser.

No Brasil, é o contrário: desde que os homens públicos não dependem do povo nem das eleições, desde que estas não decidem coisa alguma, por isso os políticos vencem graças à velhacaria, às espertezas, às astúcias, às manhas, ao malabarismo, à bajulação, à subserviência.

Sendo livres as eleições em todos os países civilizados, graças ao voto secreto, os políticos, para vencerem, não têm senão conquistar a estima, a consciência e a simpatia pública, procurando bem servir os interesses coletivos.

Não havendo eleições no Brasil ou - o que dá na mesma - não sendo estas livres, os políticos do nosso país para vencer não precisam conquistar a estima pública, nem dar satisfações ao povo, mas apenas captar as boas graças dos mandões que se apossam das posições supremas.

\footnotetext{
${ }^{11}$ Fonte: Dicionário Houaiss da Língua Portuguesa. $1^{\mathrm{a}}$ ed. Rio de Janeiro, Objetiva, 2009.
} 
Neste regime, assim falscado pela base, a degenerescência é progressivamente crescente e vem-se processando em toda a duração da República.

Para que na vida pública haja uma permanente e constante seleção dos maus elementos, é preciso que o povo, o eleitorado tenha o direito de eleger quem bem quiser, de depor um partido ou uma situação no governo, optando livremente pelos candidatos que melhor correspondam às suas aspirações. Ora, isso não se dá na política brasileira. $\mathrm{O}$ povo é obrigado a aceitar integralmente todas as chapas, de todos os governos, em todos os 21 estados do Brasil.

Sem liberdade e dignidade garantidas a cada indivíduo, não pode haver caráter nos cidadãos.

Ora, em todos os 21 estados do Brasil impera uma autocracia incompatível com a liberdade que não permite a eclosão ou a manifestação do civismo, que não consente a expansão das virtudes democráticas.

Este regime de escravidão política que impera nos 21 cacicados do Brasil, degrada o caráter de nossa raça. Só a liberdade ampla e completa viriliza, enobrece o homem. A escravidão da-lhe sentimentos servis. A tutela desviriliza os povos.

Esse processo permanente de degeneração do caráter nacional vem se elaborando e agravando dia a dia desde a fundação da República. A sua origem é a onipotência absoluta dos governos, de posse da máquina eleitoral, e a impotência absoluta do povo e da opinião pública. A sua consequência, o abastardamento completo do povo e da política brasileira. $O$ povo brasileiro assim se acostumou a viver em regime de senzala num acanalhamento geral de tudo e de todos.

Os políticos brasileiros acham que todos os processos são lícitos, mesmo os mais indecorosos, contudo que preservem as posições e os recursos delas provenientes. Cada estado do Brasil é um burgo podre em que o presidente respectivo, ao seu bel prazer, dispõe dos cargos de senadores federais e estaduais.

O caráter nacional não existe mais, chafurdou-se neste universal acanalhamento, pois que o povo não tem direito nenhum e os políticos que têm as posições, são senhores absolutos de fazerem o que quiserem sem que ninguém os possa conter. (...)

No texto analisado, mais próximo do gênero editorial, o locutor-jornalista enuncia como enunciador universal colocando uma verdade inquestionável que lhe servirá como um de seus argumentos para defender a necessidade do voto secreto no Brasil:

"Em todos os países civilizados, os políticos, estadistas e governantes, para serem eleitos e reeleitos, em quaisquer funções públicas, procuram bem servir o público(...)"

Os "países civilizados" são colocados em oposição ao Brasil, e através dessa oposição, podemos interpretar os sentidos atribuídos ao Brasil, não ditos, tal como o de "não ser um país civilizado", como inscritos numa discursividade colonialista, na qual a oposição a país civilizado pode ser também interpretada como "país selvagem". Ou seja, apesar de realizar uma crítica aos políticos que não trabalham pelo povo, mas para seus próprios interesses, esta crítica é feita a partir de uma posição-sujeito inscrita no discurso do colonizador.

Nos países civilizados, os políticos servem bem o público para serem eleitos e reeleitos porque o público tem liberdade para escolher quem quiser. Já no Brasil, aconteceria o contrário: os políticos não dependem do povo nem das eleições, eles vencem fazendo "velhacarias", etc. Segundo o locutor-jornalista isso acontece porque 
nos países civilizados as eleições são livres já que o voto é secreto enquanto que, no Brasil, as eleições não são livres, então os políticos não precisam conquistar a estima pública, mas a dos "mandões".

É então em meio a essa oposição entre países civilizados, porque elegem seus representantes pelo voto secreto, e Brasil, país não civilizado, selvagem, cujas eleições não acontecem por meio de voto secreto, encontramos a expressão: autocracia incompativel com a liberdade, referindo-se a esse modo como os políticos brasileiros conseguiam se eleger no sistema republicano uma vez que as eleições não eram "livres". Essa expressão é reescrita por substituição por sinonímia por regime de escravidão política. Os brasileiros eram escravos por serem submetidos, na República, a um modo de funcionamento político que levava ao poder governantes que não defendiam os interesses do povo e que se elegiam fazendo "velhacarias", "espertezas", "astúcias", "artimanhas", etc. A liberdade, que aparece reescrita em vários momentos do texto relacionada ao voto, como na expressão liberdade ampla de escolha, funciona na enunciação como antonímia do regime de escravidão política.

Depois, temos a reescritura de regime de escravidão política por condensação por escravidão articulada ao predicado "dá-lhe sentimentos servis" que determina o sentido de escravidão atribuindo o sentido de servilidade neste acontecimento enunciativo à escravidão. Rememora-se o sentido de servidão que designa a escravidão dos negros no passado, havendo um movimento do sentido de servidão, pois os negros serviam seus senhores, enquanto que, no caso da escravidão política, o sentido é de sentimento de servidão, isto é, os que se sentem como servos dos políticos.

Em seguida a escravidão é reescrita por substituição por "tutela" articulada, numa relação sinonímica, articulada ao predicado "desviriliza os povos". A escravidão é significada então como tutela, pois os escravos não tinham voz, não tinham direitos, eram os senhores que respondiam por eles, como se fossem incapazes. Assim seriam também os eleitores brasileiros, sem voz, sem direito à escolha de seus governantes, sem liberdade, tutelados pelos que, à revelia, se elegiam e faziam o que queriam no poder, sem levar em conta o que o povo queria. seguinte DSD:

Vejamos então como fica o sentido de escravidão neste texto através do

Autocracia incompatível com a liberdade - Regime de escravidão política

$\perp$

Sentimento de servidão $\nmid$ Escravidão - tutela - desviriliza os povos

liberdade

A escravidão é aqui especificada como política. Novamente, acontece o deslizamento de sentidos, agora de servidão (dos negros) memorável que é trazido para o presente do acontecimento como sentimento de servidão do povo brasileiro que ocorre no regime republicano. Novamente, a antonímia se forma com o sentido da liberdade, que no acontecimento enunciativo, é relacionada com a liberdade que voto secreto proporciona por poder se escolher os governantes e não ser coagido a fazê-lo.

O domínio semântico da palavra escravidão neste artigo jornalístico de fevereiro de 1926 apresenta uma sinonímia entre as expressões autocracia incompativel com liberdade e regime de escravidão política de forma a atribuir uma identidade de sentido entre o regime de escravidão e a eleição de governantes no regime republicano que garantia a manutenção do poder para uma elite. 
Trata-se então de, através do que significa escravidão, atribuir seus sentidos ao modo de eleição do regime republicano. Na situação política do país daquele momento o eleitor brasileiro era o servo tutelado. De forma indireta, não explícita, rememora-se o chamado "voto de cabresto", prática de coação dos patrões sobre o voto de seus empregados que acontecia com frequência.

É interessante notar que, apesar da crítica, o locutor-jornalista inscreve-se numa posição-sujeito do discurso do colonizador, ao trazer como argumentos a incivilidade do Brasil em comparação com outros países.

Dessa posição, regime de escravidão política é designada, no texto, produzindo-se uma sinonímia com "autocracia incompatível com a liberdade", ou seja, poderíamos interpretar a forma de eleição na primeira República como um regime de escravidão política.

\section{Considerações Finais}

Como vimos, a escravidão é ressignificada no presente do acontecimento enunciativo dos textos analisados, havendo deslizamentos de sentido. Certos sentidos da escravidão dos africanos no Brasil são rememorados e trazidos para outras situações como para tratar do espiritualismo, do fascismo, do operariado eleitor e do sistema eleitoral da Republica.

No caso do texto que trata do espiritualismo, temos a expressão "escravizar a consciência", distinguindo-se da escravidão dos corpos dos africanos para o trabalho.

No recorte que fala da escravidão pelo fascismo, é interessante destacar que se trata de um "estado de escravidão", um deslizamento de sentido em que o substantivo "estado" atribui à escravidão o sentido de condição temporária resultante do fascismo na Itália.

$\mathrm{Na}$ análise do texto intitulado "Operariado", temos que escravidão designa, dentre outras coisas, "feudalismo escravocrata", que rememora os sentidos da relação de submissão entre o senhor, dono da terra, e vassalo, o que cultiva a terra, assim como é rememorada depois a relação de servidão do escravo africano. Estes memoráveis significam a escravidão nesse acontecimento, para depois sustentar a comparação do operariado eleitor "obediente e servil" ao senhor doutor. O interessante é que essa designação é realizada a partir de uma posição-sujeito de oposição à classe dos "senhores doutores" e à própria classe operária, embora o locutor enuncie como locutoroperário.

Já no último recorte, temos a crítica ao regime republicano brasileiro, que já apareceu em outros artigos do Jornal da Noite. A escravidão designa "tutela", "sentimento de servidão", ela "desviriliza os povos", e, é determinada também por "autocracia incompatível com a liberdade" porque os eleitores não tinham liberdade de escolha dos representantes políticos pela impossibilidade do voto secreto. Embora critique e denuncie um problema grave que acaba abalando o sistema republicano que teria como vantagem justamente o poder de escolha dos seus representantes, diferentemente da Monarquia, o locutor-jornalista opõe o Brasil aos "países civilizados", de forma que enuncia inscrito no discurso do colonizador para realizar a crítica ao sistema eleitoral na República.

Enfim com exceção do primeiro recorte, os demais têm em seu domínio semântico a antonímia com a liberdade.

Vemos, então, que escravidão é reescrita no presente dos acontecimentos enunciativos dos textos do início do século XX, em meados dos anos 20 , ressignificada nas condições políticas do momento, perdendo, aos poucos, a relação com a escravidão 
dos africanos para derivar para outras formas de escravidão como a escravidão política, dentre outras situações, de forma a sustentar críticas, como a do sistema eleitoral do regime republicano.

\section{REFERÊNCIAS}

ELIAS DE OLIVEIRA, S. Sobre o funcionamento do político na linguagem. In: Línguas e Instrumentos Linguísticos. No 34- jan-jun 2014.

FOURNEL, J. L.; ZANCARINI, J. C.; DESCENDRE, R. Estudos sobre a língua política: filologia e política na Florença do século XVI. Cáceres, Editora Unemat; Lyon, ANR-TRIAngle; Campinas, Editora RG, 2008.

GUIMARÃES, E. Semântica do Acontecimento. Campinas, Pontes, 2002.

Domínio Semântico de Determinação. In: Guimarães, E.; Mollica, M. C.(Orgs). A Palavra: forma e sentido. Campinas: Pontes; RG Editores, 2007.

HOUAISS, A.; VILLAR, M. de S. Dicionário Houaiss da língua portuguesa. $1^{\mathrm{a}}$ ed. Rio de Janeiro: Objetiva, 2009.

NOGUEIRA, L. Competências: individual, coletivo ou corporativo? Análise do dicionário de competências - Petrobrás. In: Entremeios: revista de estudos do discurso. No 05, jul/ 2012. Disponível em: http://www.entremeios.inf.br/published/77.pdf. Acesso em: 28/09/2017.

PAULA MACHADO, C. de. Semântica e Enunciação: a designação da palavra escravidão em artigos do jornal Folha da Noite do início do século XX. In: Entrepalavras: Revista de linguística, Fortaleza, Ceará. Universidade Federal do Ceará (UFC). Vol. 07, $\mathrm{n}^{\mathrm{o}}$ 1(7), 2017. Disponível em: http://www.entrepalavras.ufc.br/revista/index.php/Revista/article/view/934. Acesso em: 28/09/2017.

Recebido em: agosto de 2017.

Aprovado em: outubro de 2017.

Como citar este trabalho:

MACHADO, C. de P. O movimento dos sentidos de escravidão em artigos jornalísticos do Jornal Folha da Manhã do início do século XX. Traços de linguagem, v. 1, n. 2, p. 50-60, 2017. 